\title{
High Responsivity and External Quantum Efficiency Photodetectors Based on Solution-Processed Ni-Doped CuO Films
}

Wenlei Yin, ${ }^{\dagger}$ Jiayan Yang, ${ }^{\dagger}$ Keyang Zhao, ${ }^{\dagger}$ Anyang Cui, ${ }^{\dagger}$ Jiaoyan Zhou, ${ }^{\dagger}$ Wei Tian,,${ }^{\S}$ Wenwu Li, $,{ }^{*}, t$

Zhigao $\mathrm{Hu},{ }^{\dagger,+}$ and Junhao $\mathrm{Chu}^{\dagger,+}$

$\dagger$ Engineering Research Center of Nanophotonics \& Advanced Instrument (MOE), Technical Center for Multifunctional Magneto-Optical Spectroscopy (Shanghai), School of Physics and Electronic Science, East China Normal University, Shanghai 200241, China

$\$$ Shanghai Institute of Intelligent Electronics \& Systems, Fudan University, Shanghai 200433, China

$\S$ School of Physical Science and Technology, Jiangsu Key Laboratory of Thin Films, Soochow University, Suzhou 215006, China

* Corresponding author. E-mail: wwli@ee.ecnu.edu.cn 

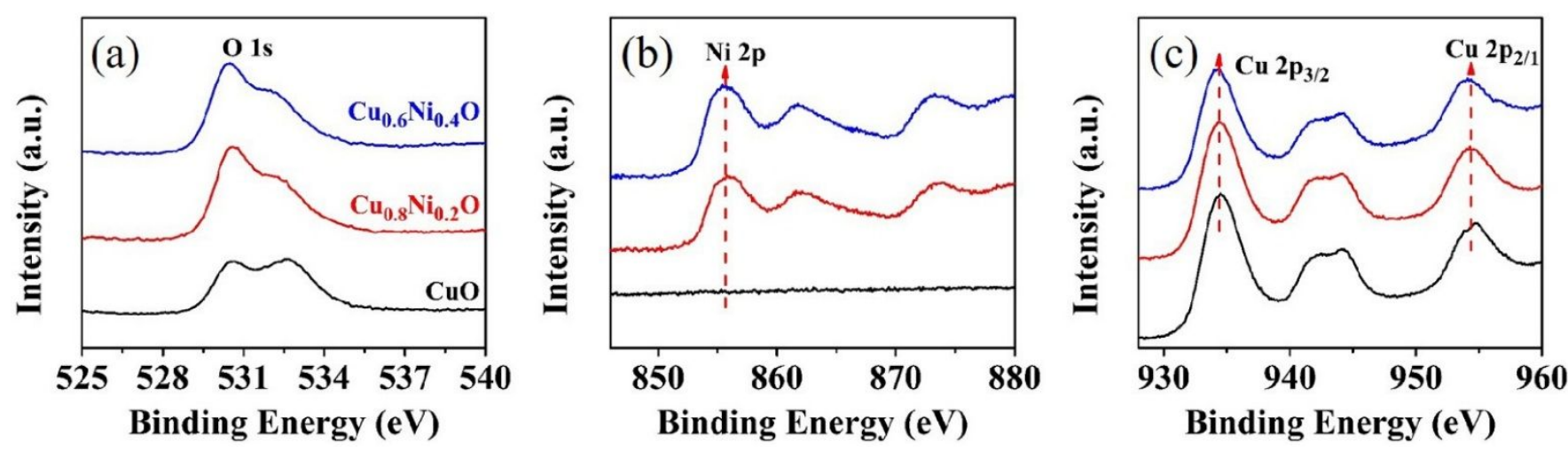

Figure S1. The XPS spectra of (a) the O 1s, (b) the Ni 2p, and (c) the $\mathrm{Cu} 2 \mathrm{p}$ elements for $\mathrm{Cu}_{1-\mathrm{x}} \mathrm{Ni}_{\mathrm{x}} \mathrm{O}(\mathrm{x}=0$, 0.2 , and 0.4 ) films. 

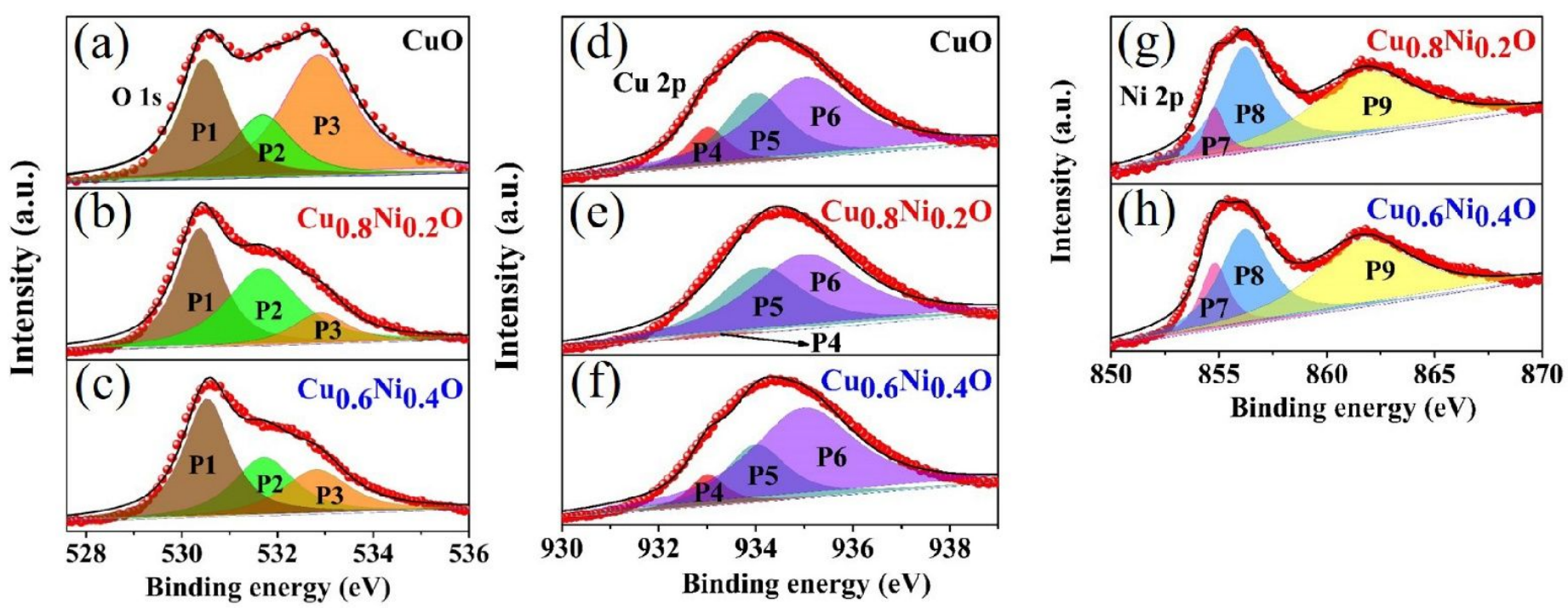

Figure S2. The deconvolution XPS spectra of $\mathrm{O} 1 \mathrm{~s}$ for (a) $\mathrm{CuO}$; (b) $\mathrm{Cu}_{0.8} \mathrm{Ni}_{0.2} \mathrm{O}$; (c) $\mathrm{Cu}_{0.6} \mathrm{Ni}_{0.4} \mathrm{O}$ films; (d)-(f) The deconvolution XPS spectra of $\mathrm{Cu} 2 \mathrm{p}$ for $\mathrm{Cu}_{1-\mathrm{x}} \mathrm{Ni}_{\mathrm{x}} \mathrm{O}(\mathrm{x}=0,0.2$, and 0.4) films; (g)-(h) The deconvolution XPS spectra of $\mathrm{Ni} 2 \mathrm{p}$ for $\mathrm{Cu}_{0.8} \mathrm{Ni}_{0.2} \mathrm{O}$ and $\mathrm{Cu}_{0.6} \mathrm{Ni}_{0.4} \mathrm{O}$ film. 

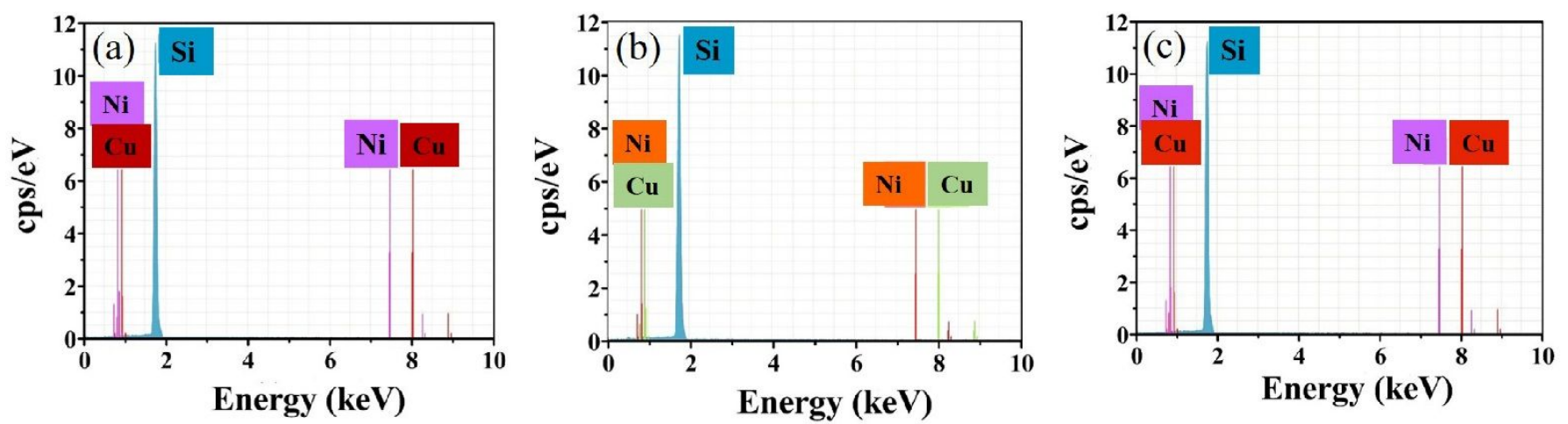

(d)

\begin{tabular}{|c|c|c|c|}
\hline Element & $\mathrm{At} \%$ & $\mathrm{Cu}_{0.8} \mathrm{Ni}_{0.2} \mathrm{O}$ & $\mathrm{Cu}_{\mathbf{0 .}} \mathbf{N i}_{\mathbf{0 . 4}} \mathrm{O}$ \\
\hline $\mathrm{Cu}$ & 100 & 79.8 & 62.7 \\
\hline $\mathrm{Ni}$ & 0 & 20.2 & 37.3 \\
\hline
\end{tabular}

Figure S3. The EDS spectrum of $\mathrm{Cu}$ and $\mathrm{Ni}$ elements in the $\mathrm{Cu}_{1-\mathrm{x}} \mathrm{NiO}_{\mathrm{x}} \mathrm{O}$ films (a) $\mathrm{x}=0$; (b) $\mathrm{x}=0.2$; (c) $\mathrm{x}=0.4$. (d) The atomic ratio of $\mathrm{Cu}$ and $\mathrm{Ni}$ in the $\mathrm{CuO}, \mathrm{Cu}_{0.8} \mathrm{Ni}_{0.2} \mathrm{O}$, and $\mathrm{Cu}_{0.6} \mathrm{Ni}_{0.4} \mathrm{O}$ films. 

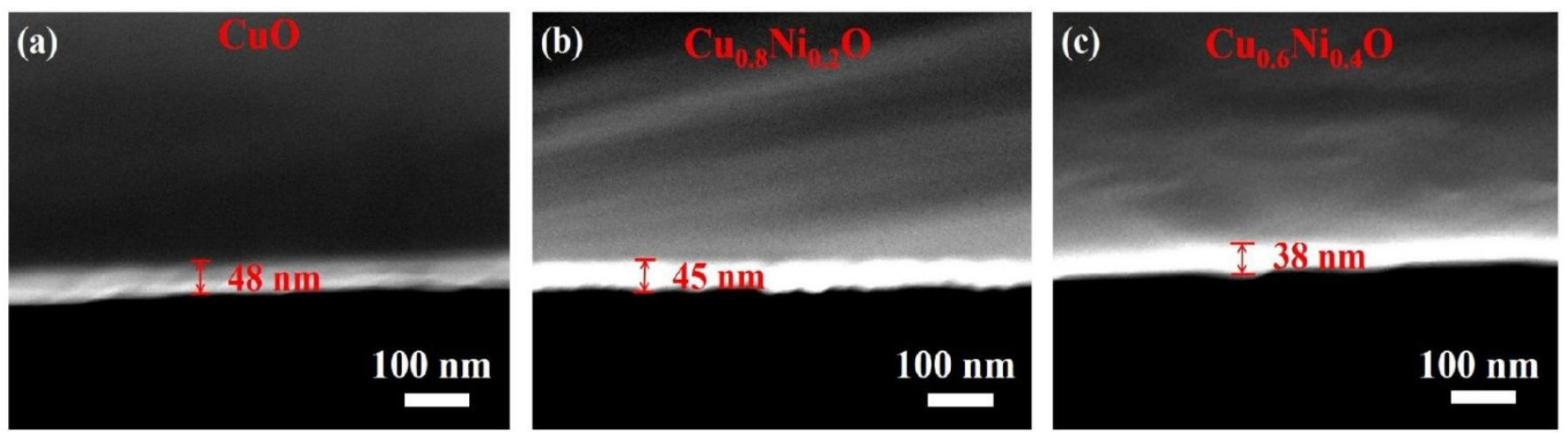

Figure S4. (a)-(c) The SEM images of $\mathrm{Cu}_{1-x} \mathrm{Ni}_{x} \mathrm{O}(x=0,0.2$, and 0.4$)$ films to estimate the thickness. 


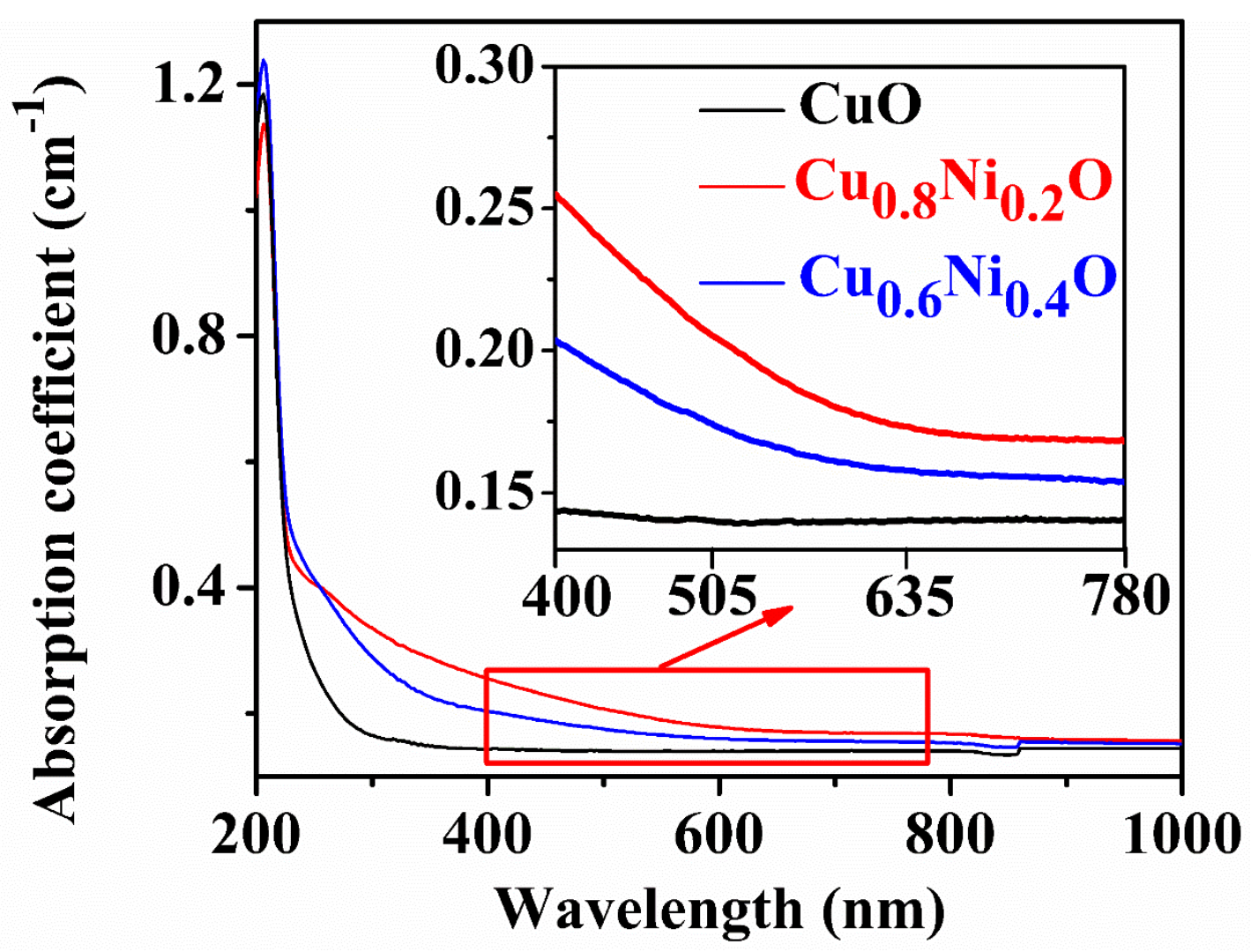

Figure S5. The absorption spectra of the $\mathrm{CuO}, \mathrm{Cu}_{0.8} \mathrm{Ni}_{0.2} \mathrm{O}$, and $\mathrm{Cu}_{0.6} \mathrm{Ni}_{0.4} \mathrm{O}$ films. Inset shows the enlarge absorption spectra of the films at the wavelength range of $400-780 \mathrm{~nm}$, corresponding to the illumination range of laser sources. 

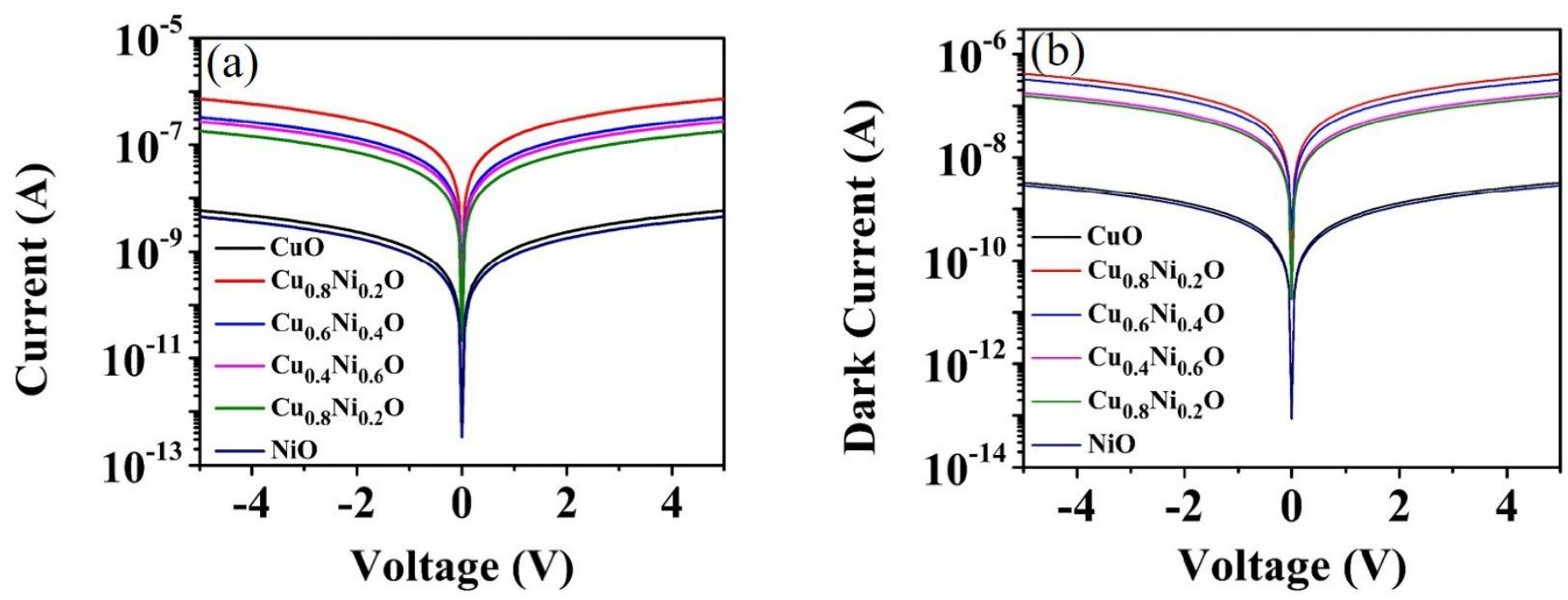

Figure S6. (a) Photocurrent of $\mathrm{Cu}_{1-\mathrm{x}} \mathrm{Ni}_{\mathrm{x}} \mathrm{O}(\mathrm{x}=0,0.2,0.4,0.6,0.8$, and 1) film photodetectors under $635 \mathrm{~nm}$ laser illumination. The light power density is $5 \mathrm{~mW} / \mathrm{cm}^{2}$; (b) Dark current of $\mathrm{Cu}_{1-\mathrm{x}} \mathrm{Ni}_{\mathrm{x}} \mathrm{O}(\mathrm{x}=0,0.2,0.4,0.6$, 0.8 , and 1) film photodetectors without illumination. 